\title{
Stability in the rumen and effect on plasma status of single oral doses of vitamin $D$ and vitamin $E$ in high-yielding dairy cows
}

\author{
L. Hymøller ${ }^{1}$ and S. K. Jensen \\ Department of Animal Health and Bioscience, Aarhus University, Faculty of Agricultural Sciences, DK-8830 Tjele, Denmark
}

\begin{abstract}
The ruminal fate of the fat-soluble vitamins $\mathrm{D}$ and $\mathrm{E}$ was studied in dairy cows. Ten to $15 \mathrm{~kg}$ of ruminal contents was taken from each cow through a ruminal fistula. A sample was taken out (0-h sample) and the rest of the contents were mixed with 4,360 $\mathrm{mg}$ of all-rac$\alpha$-tocopheryl acetate (vitamin E; study 1) or $4,360 \mathrm{mg}$ of all-rac- $\alpha$-tocopheryl acetate, $250 \mathrm{mg}$ of ergocalciferol (vitamin $\mathrm{D}_{2}$ ), and $250 \mathrm{mg}$ of cholecalciferol (vitamin $\mathrm{D}_{3}$; study 2). After mixing, the ruminal contents were returned to the respective cows. Blood was collected $0,6,24$, and $30 \mathrm{~h}$ after introducing the vitamins into the rumen. Samples of ruminal contents were collected at $0,1,2,4,6,24$, and $30 \mathrm{~h}$ (in vivo). From the 1-h sample, 6 subsamples from each cow were incubated at $37^{\circ} \mathrm{C}$ and taken out at $2,4,6,12,24$, and $30 \mathrm{~h}$ (in vitro). In vivo concentrations of added $\alpha$-tocopherol, ergocalciferol, and cholecalciferol in the rumen first increased and subsequently declined due to dilution effects of eating and passage out of the rumen. The level of the free-alcohol form of $\alpha$-tocopherol from the natural content in feed was constant throughout the in vivo study, in contrast to the content of total $\alpha$-tocopherol, which indicated that no hydrolysis of the acetate form into alcohol form happened in the rumen. In vitro, all added vitamins were found at constant levels; hence, none of the added vitamins were degraded in ruminal contents. The concentration of $\alpha$-tocopherol in plasma increased at a rate per milligram of ruminally introduced $\alpha$-tocopherol below the rate of the increase in plasma ergocalciferol or cholecalciferol metabolites per milligram of introduced ergocalciferol or cholecalciferol, respectively, over $24 \mathrm{~h}$. In conclusion, ergocalciferol, cholecalciferol, and $\alpha$-tocopheryl acetate proved to be stable in the rumen and in ruminal contents from highyielding dairy cows. Changes in plasma concentrations of the vitamins relative to the amount of vitamin introduced to the rumen indicated a lower effect on plasma status of ergocalciferol than of cholecalciferol, and an
\end{abstract}

Received April 13, 2010.

Accepted September 1, 2010.

${ }^{1}$ Corresponding author: Lone.Hymoller@agrsci.dk even lower effect of $\alpha$-tocopherol. The limited plasma response after a single dose of $\alpha$-tocopheryl acetate led to the conclusion that oral single dose therapy with all-rac- $\alpha$-tocopheryl acetate is of limited physiological value.

Key words: fat-soluble vitamins, ergocalciferol, rumen degradation, single oral dose therapy

\section{INTRODUCTION}

In dairy cows, the forestomachs, particularly the rumen with its fermentative environment, are regarded as a major site for the degradation and chemical alteration of many feed constituents, including some micronutrients like vitamins. In the literature, fat-soluble vitamins are often reported to be destroyed in the rumen before they can be taken up by the bloodstream from the intestines. This is believed to be the main reason for the very low plasma occurrence of a given dose of, for example, $\alpha$-tocopherol (vitamin E) in ruminants (Bourne et al., 2007).

$\alpha$-Tocopherol exists in 8 different isomeric configurations: $R S S, R R S, R R R, R S R$, and 4 with $2 S$ configuration. The $R R R$ isomer is the form occurring in nature, whereas synthetic $\alpha$-tocopherol used for feed additives consists of a racemic mixture (all-rac) of all 8 isomers. Furthermore, synthetic $\alpha$-tocopherol is acetylated to protect its alcohol group from oxidation. Both ergocalciferol (vitamin $\mathrm{D}_{2}$ ) and cholecalciferol (vitamin $\mathrm{D}_{3}$ ) are common vitamin D types in ruminants. Ergocalciferol is naturally produced in plant material used as roughage for cattle when ergosterol from fungi growing on the plant material is exposed to sunlight during curing at harvest (Richardson and Logendra, 1997). Cholecalciferol is either produced endogenously in the skin of the animals during exposure to sunlight, thus never entering the digestive tract, or provided in the feed as synthetic additives. Both ergocalciferol and cholecalciferol must undergo hydroxylation in the liver and the kidneys to become physiologically active. From ergocalciferol and cholecalciferol, the liver produces $25(\mathrm{OH})$-ergocalciferol or $25(\mathrm{OH})$-cholecalciferol, respectively, which are the main metabolites circulating in plasma and their concentration is indicative of the physiological vitamin D status of an animal. 
Early research suggested that fat-soluble vitamins supplemented in the diet of ruminants were degraded in the rumen. Up to $45 \%$ of dietary added $\alpha$-tocopherol could not be accounted for in abomasal contents of sheep (Alderson et al., 1971), and only 10 to $25 \%$ of added ergocalciferol and cholecalciferol was recovered after 24 $\mathrm{h}$ of incubation in intact ruminal fluid (Sommerfeldt et al., 1979, 1980). The amount of $\alpha$-tocopherol lost appeared to increase with increasing starch levels in the feed (Alderson et al., 1971) and depended on the form of $\alpha$-tocopherol used as more $\alpha$-tocopherol was lost in the rumen when administered as all-rac- $\alpha$-tocopherol (alcohol) than when administered as all-rac- $\alpha$-tocopheryl acetate (acetate ester) (Shin and Owens, 1990).

With respect to $\alpha$-tocopherol, later findings have suggested that the results of Alderson et al. (1971) might have been due to incomplete extraction of $\alpha$-tocopherol from the duodenal contents analyzed in their experiments (Leedle et al., 1993). Later experiments have not been able to show degradation of $\alpha$-tocopherol, neither when given as all-rac- $\alpha$-tocopheryl acetate in the rumen nor during in vitro incubation of all-rac- $\alpha$-tocopheryl acetate in ruminal fluid or contents from sheep or cattle (Leedle et al., 1993; McDiarmid et al., 1994; Weiss et al., 1995; Chikunya et al., 2004). It is therefore commonly held that $\alpha$-tocopherol is stable in the ruminal environment, whereas the fate of ergocalciferol and cholecalciferol in the rumen is still unresolved.

Absorption of $\alpha$-tocopherol, ergocalciferol, and cholecalciferol is assumed to take place in the small intestine by passive diffusion following the fat fraction of the feed aided by bile salts, but the exact nature of the process is not fully established. In contrast to the absorption of ergocalciferol and cholecalciferol, absorption of synthetic $\alpha$-tocopherol from all-rac- $\alpha$-tocopheryl acetate in the small intestine requires hydrolyzation of the acetate ester into the alcohol form of the vitamin (Jensen et al., 1999). Whereas it has never been shown whether hydrolysis of the acetate form takes place in the rumen, catalyzed by ruminal esterase enzymes, it is well established that supplementation with the natural $R R R$ isomer results in higher serum concentrations of $\alpha$-tocopherol than supplementation with synthetic isomers (Hidiroglou et al., 1992; Meglia et al., 2006).

In practical farming, advisors and veterinarians often recommend a high single-dose oral treatment with fat-soluble vitamins to avoid injections. However, the physiological effect of high doses of $\alpha$-tocopherol is not satisfactorily described in the literature. Previous experiments have rendered inconsistent outcomes regarding the ruminal stability and biological efficiency of fat-soluble vitamins in ruminants. The following experiment was carried out to elucidate the fate of single doses of ergocalciferol, cholecalciferol, and all-rac- $\alpha-$ tocopheryl acetate in the rumen of high-yielding dairy cows, together with the plasma response to single-dose therapy with the respective vitamins.

\section{MATERIALS AND METHODS}

Ruminal fate and plasma occurrence of fat-soluble vitamins were explored in 2 different studies. Study 1 concerned the rumen degradation and plasma occurrence of stereoisomers of synthetic all-rac- $\alpha$-tocopherol depending on the feed starch source and was carried out in a crossover design with 2 starch sources and 2 periods. Study 2 concerned the rumen degradation of ergocalciferol, cholecalciferol, and $\alpha$-tocopherol together with the plasma occurrence of ergocalciferol, cholecalciferol, 25( $\mathrm{OH})$-ergocalciferol, 25( $\mathrm{OH})$-cholecalciferol, and $\alpha$-tocopherol.

\section{Animals}

Four high-yielding Holstein cows fitted with ruminal fistulas were used in study 1 , and 5 cows were used in study 2. The cows were slaughtered by the end of study 2. The studies were carried out at the Faculty of Agricultural Sciences at Aarhus University in Tjele, Denmark, and the experiments complied with the Danish Ministry of Justice Law No. 726 (September 9, 1993) concerning experiments with animals and care of experimental animals.

\section{Housing, Diet, and Management}

All cows were housed in a tie stable without access to sunlight and milked twice a day at approximately 12 -h intervals. During study 1, the cows were fed a grass silage-based TMR where the main source of starch was rolled wheat (Roll diet) or sodium hydroxide-treated wheat $(\mathrm{NaOH}$ diet). The rations consisted of $50 \%$ perennial ryegrass and white clover silage, $5 \%$ soybean meal, a vitamin and mineral mixture, and either $42 \%$ rolled wheat or $43 \%$ sodium hydroxide-treated wheat in a crossover design. The starch content for the Roll diet was $282 \mathrm{~g} / \mathrm{kg}$ of DM, and $227 \mathrm{~g} / \mathrm{kg}$ of DM for the $\mathrm{NaOH}$ diet. In study 2 , the cows were fed a corn-based TMR consisting of $40 \%$ corn silage, $31 \%$ perennial ryegrass and white clover silage, $13 \%$ rapeseed cake, $9 \%$ sugar beet pellets and molasses, $6 \%$ barley, and a vitamin and mineral mixture. The cows were fed twice a day at 0700 and $1630 \mathrm{~h}$.

\section{Treatments}

On the first day of a given study (study period in study 1), 10 to $15 \mathrm{~kg}$ of ruminal contents was taken out 
through the rumen fistula of each cow. A sample was taken out (0-h sample) and the rest of the ruminal contents were mixed with 4,360 $\mathrm{mg}$ of all-rac- $\alpha$-tocopheryl acetate from Rovimix E 50 SD (DSM, Brøndby, Denmark) in study 1 , and $250 \mathrm{mg}(10,000,000 \mathrm{IU})$ of both ergocalciferol and cholecalciferol from Fluca (Buchs, Switzerland) and 4,360 $\mathrm{mg}$ of all-rac- $\alpha$-tocopheryl acetate from Rovimix E 50 SD in study 2. Vitamins were dissolved in $60 \mathrm{~mL}$ of $50 \%$ ethanol before mixing with the ruminal contents. After thorough mixing of the vitamin solutions into the ruminal contents, the contents were returned to the rumen of the respective cows.

\section{Samples}

In Vivo Rumen Samples. One hour after placing the vitamins in the rumen, a sample of ruminal contents weighing approximately $1 \mathrm{~kg}$ was taken out by hand from different areas of the rumen (1-h sample). This procedure was repeated at 2, 4, 6, 24, and $30 \mathrm{~h}$ after introducing the vitamin solutions into the rumen. Samples were immediately placed on ice and subsequently freeze-dried and stored at $-18^{\circ} \mathrm{C}$ until analysis.

In Vitro Rumen Samples. An aliquot of the ruminal contents from the 1-h sample was put in $100-\mathrm{mL}$ plastic bottles and placed in a water bath at $37^{\circ} \mathrm{C}$ in a dark laboratory. The lid of the bottles was punctured with an injection needle and a syringe was fitted on top of the needle to allow gas to escape from the bottles without allowing atmospheric air to reach the ruminal contents. The bottles were removed from the water bath at 2, 4, 6, 12, 24, and $30 \mathrm{~h}$ after introducing the vitamin solutions into the rumen of the cows. Samples were freeze-dried and stored at $-18^{\circ} \mathrm{C}$ until analysis.

Blood Samples. Blood was collected at 0, 6, 24, and $30 \mathrm{~h}$ after introducing the vitamin solutions into the rumen of the cows, and in study 2 , blood was also collected at slaughter between 72 and $120 \mathrm{~h}$ after starting the study. Samples were collected in EDTA-coated Vacutainer tubes. Samples were centrifuged for $10 \mathrm{~min}$ at $1,500 \times g$, and the plasma was transferred to sample tubes and stored at $-18^{\circ} \mathrm{C}$ until analysis.

\section{Chemical Analysis}

All analyses were performed in the Faculty of Agricultural Sciences laboratories (Aarhus University). All samples and standard vitamin solutions were protected from light during preparation.

Water quality was secured at all times by treatment on a Milli-Q 185 filter provided by Millipore S.A.S. (Molsheim, France). Methanol and heptane of HPLC grade were purchased from POCH S.A. (Gliwice, Poland), and acetonitrile of HPLC far UV grade was purchased from Lab-Scan Ltd. (Dublin, Ireland). Ethanol 96\% was purchased from Danisco (Copenhagen, Denmark). L(+)-Ascorbic acid was purchased from J.T. Baker (Deventer, the Netherlands) and $40 \mathrm{~g}$ was dissolved in $200 \mathrm{~mL}$ of water to obtain a $20 \%$ (wt/vol) solution. The ascorbic acid solution was prepared fresh every week and stored protected from light. Potassium hydroxide purchased from ApliChem (Darmstadt, Germany) was prepared in fresh $50 \%$ (wt/vol) solutions with water every month. The HPLC-grade $1 \alpha(\mathrm{OH})$ cholecalciferol used as the internal standard in all vitamin D analyses was purchased from Fluka (Buchs, Switzerland) and dissolved in ethanol in a 1,000 ng/ $\mathrm{mL}$ solution.

Ruminal Contents. Ruminal contents were analyzed for total $\alpha$-tocopherol, free $\alpha$-tocopherol, $\beta$-carotene, lutein, ergocalciferol, and cholecalciferol. Two grams of freeze-dried ruminal contents was placed in a flat-bottomed flask and $70 \mathrm{~mL}$ of ethanol $96 \%, 30$ $\mathrm{mL}$ of methanol, $30 \mathrm{~mL}$ of ascorbic acid-water $20 \%$, and $20 \mathrm{~mL}$ of potassium hydroxide-water $50 \%$ were added and saponified for $30 \mathrm{~min}$ at $80^{\circ} \mathrm{C}$. Samples were rapidly cooled in cold water and $2 \mathrm{~mL}$ of the sample was transferred to 4 culture tubes and $1 \mathrm{~mL}$ of water was added. Two samples were used as doubles to analyze for vitamin $\mathrm{D}$, and 2 were used to analyze for the other vitamins and metabolites. The samples for vitamin $\mathrm{D}$ analysis were added to $150 \mu \mathrm{L}$ of internal standard solution and all samples were extracted 2 times with 5 $\mathrm{mL}$ of heptane.

Heptane fractions were quantitatively transferred to a clean culture tube after centrifugation at $1,500 \times g$ for $10 \mathrm{~min}$ in a Hettich Rotant A/S type 3510 centrifuge from Hettich Zentrifugen (Tuttingen, Germany) and analyzed by HPLC as described by Jensen et al. (1998) and Jensen and Lauridsen (2007). In addition to analysis for the total $\alpha$-tocopherol content after saponification, an extraction was performed without preceding saponification to analyze only the free $\alpha$-tocopherol present in the sample.

The heptane fractions for vitamin $\mathrm{D}$ analysis were evaporated to exact dryness over $\mathrm{N}_{2}$ at $40^{\circ} \mathrm{C}$ in a Supertherm vaporizer from Mikrolab Aarhus A/S (Højbjerg, Denmark). The samples were redissolved in $200 \mu \mathrm{L}$ of methanol-water $90 \%$ (vol/vol), vortex mixed, centrifuged at $1,500 \times g$ for $10 \mathrm{~min}$, transferred to micro vials, and analyzed by HPLC as described by Hymøller et al. (2009).

Plasma. Total $\alpha$-tocopherol, stereoisomers of $\alpha$-tocopherol, $\beta$-carotene, and lutein in plasma were analyzed by HPLC according to methods described previously by Jensen et al. (1998) and Jensen and Lauridsen (2007). The 4 stereoisomers of $2 \mathrm{~S}$ form were not separated by the method used. Ergocalciferol, 




Figure 1. Total $\alpha$-tocopherol, free $\alpha$-tocopherol, $\beta$-carotene, and lutein in ruminal content during a 30 -h in vivo study depending on the feed starch source $(\mathrm{NaOH}=$ sodium hydroxide treated wheat; Roll = rolled wheat) after introducing 4,360 mg of all-rac- $\alpha$-tocopheryl acetate into the rumen at $0 \mathrm{~h}$.

cholecalciferol, 25(OH)-ergocalciferol, and 25(OH)cholecalciferol was analyzed by HPLC as described by Hymøller et al. (2009).

\section{Statistical Analysis}

Results from the ruminal contents samples in the in vitro study were analyzed in the GLM procedure of the SAS system (SAS Institute Inc., Cary, NC) to test if curve slopes were significantly different from 0 . Plasma results were compared by Student's 2-sample, 2-tailed, homoscedastic $t$-test.

\section{RESULTS}

\section{Vitamins in Ruminal Contents}

Results from the ruminal contents regarding total and free $\alpha$-tocopherol, $\beta$-carotene, and lutein from the in vivo and in vitro parts of study 1 are shown in Figures 1 and 2, respectively. Results regarding ergocalciferol, cholecalciferol, $\alpha$-tocopherol, $\beta$-carotene, and lutein from the in vivo and in vitro parts of study 2 are shown in Figures 3 and 4, respectively.

In study 1, no differences were found in the concentration of total or free $\alpha$-tocopherol in the rumen in vivo or the ruminal contents in vitro depending on the starch source in the TMR. In vivo, the concentration of the added total $\alpha$-tocopherol, cholecalciferol, and ergocalciferol declined because of the dilution effect of subsequent eating and disappearance of vitamins out of the rumen with the ruminal contents. Lutein and $\beta$-carotene originating from the natural content in the feed was found at a constant level (Figures 1 and 3). In vitro, both the added vitamins and the natural feedderived $\beta$-carotene and lutein were found at constant levels (Figures 2 and 4 ). In vitro, some fluctuation did occur in the added vitamins, as is often seen in in vitro incubation studies, but linear fits revealed slopes were not significantly different from zero in both study 1 ( $P$ $>0.5)$ and study $2(P>0.2)$.

To obtain information about any hydrolysis of $\alpha$-tocopheryl acetate in ruminal fluid, both free $\alpha$-tocopherol and total $\alpha$-tocopherol were analyzed. Free $\alpha$-tocopherol was determined as the amount of $\alpha$-tocopherol extracted from ruminal fluid without preceding saponification. In the in vivo samples, the total content of $\alpha$-tocopherol increased after the addition of $\alpha$-tocopheryl acetate to the rumen, and declined due to subsequent dilution from feed intake and disappearance out of the rumen. By contrast, the level of the free alcohol form of $\alpha$-tocopherol, originating from the natural content in the feed, was constant throughout the study, indicating that no hydrolysis of the acetate form took place in the rumen (Figure 1). 


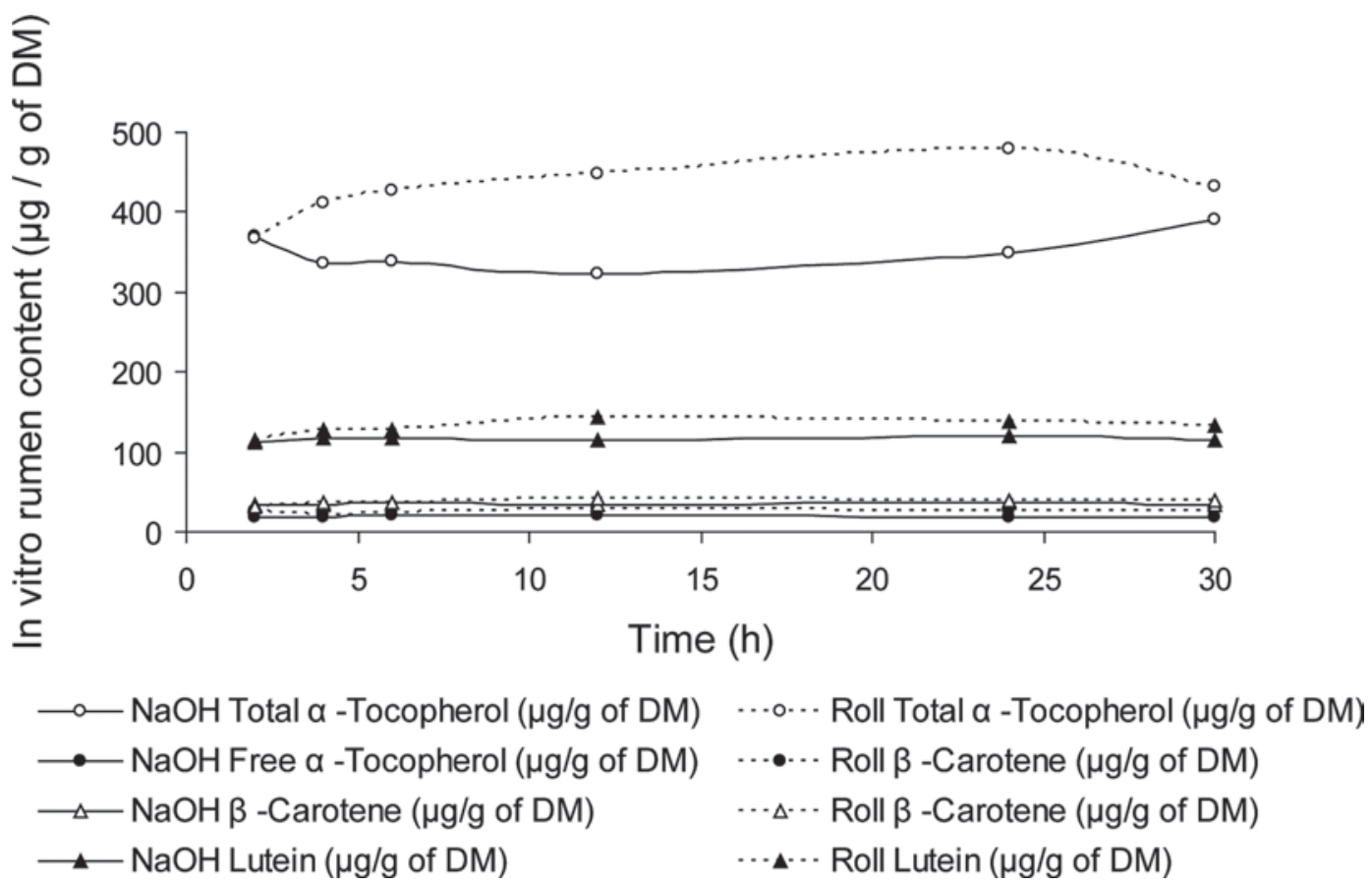

Figure 2. Total $\alpha$-tocopherol, free $\alpha$-tocopherol, $\beta$-carotene, and lutein in ruminal content during a 30 -h in vitro study depending on the feed starch source $(\mathrm{NaOH}=$ sodium hydroxide treated wheat; Roll = rolled wheat). Slopes are not significantly different from zero in linear fits $(P>0.5)$.

\section{Vitamins in Plasma}

Plasma results for cholecalciferol, ergocalciferol, and their derived 25-hydroxylated metabolites are shown in Table 1. Plasma concentrations of both ergocalciferol and cholecalciferol increased rapidly within the first hours of the study, from undetectable amounts at 0 $\mathrm{h}$, to peak concentrations of $99 \pm 15$ and $163 \pm 16$ $\mathrm{ng} / \mathrm{mL}$, respectively, after $24 \mathrm{~h}$. The concentration of cholecalciferol was higher than the concentration of ergocalciferol at all sampling times after the 0-h sample $(P \leq 0.05)$.
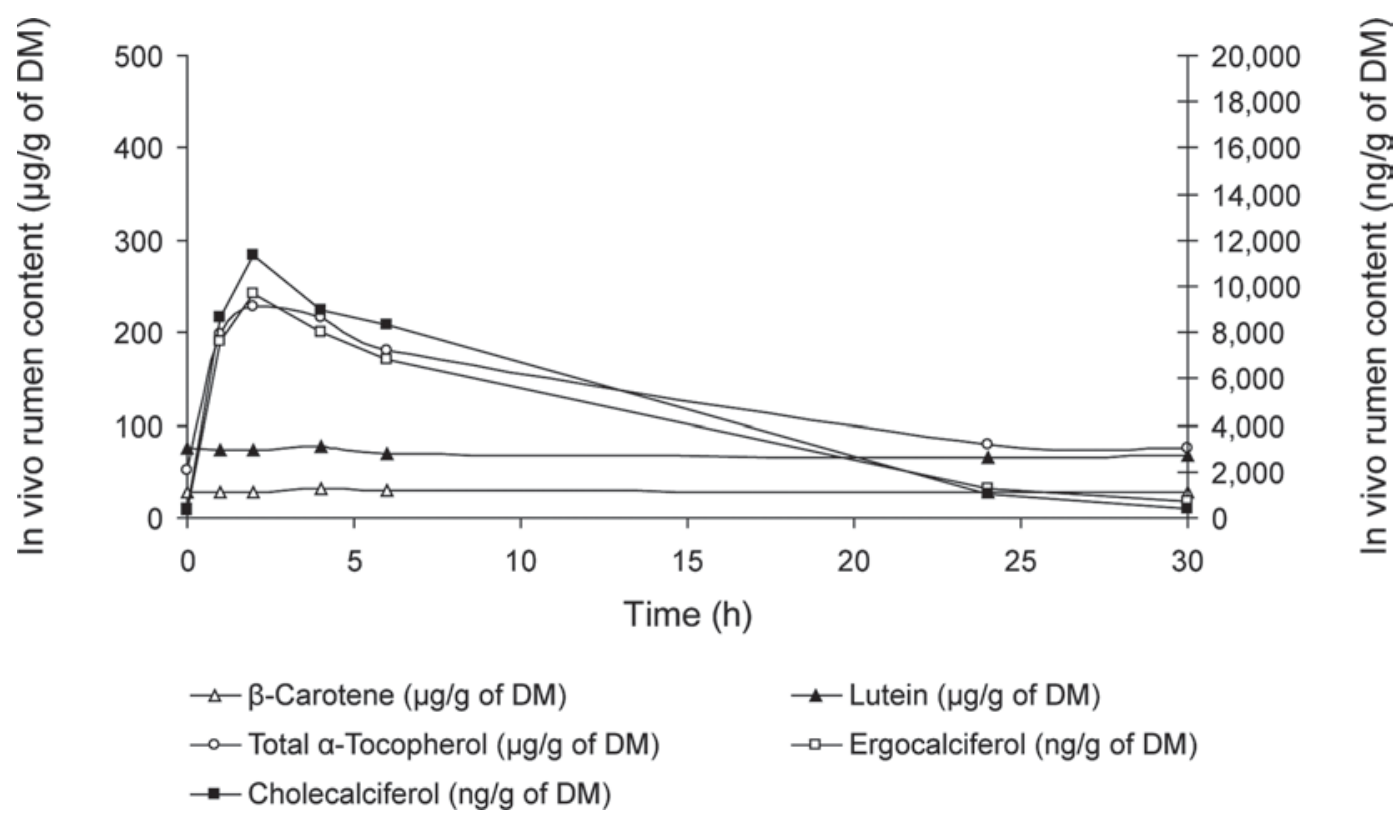

Figure 3. Ergocalciferol, cholecalciferol, $\alpha$-tocopherol, $\beta$-carotene, and lutein in ruminal content during a 30-h in vivo study after introducing $250 \mathrm{mg}(10,000,000 \mathrm{IU})$ of cholecalciferol and ergocalciferol, and 4,360 $\mathrm{mg}$ of all-rac- $\alpha$-tocopheryl acetate into the rumen at $0 \mathrm{~h}$. 
Table 1. Plasma concentrations (mean $\pm \mathrm{SD}$ ) of vitamin $\mathrm{D}$ metabolites, total $\alpha$-tocopherol, and $\beta$-carotene

\begin{tabular}{|c|c|c|c|c|c|c|}
\hline Item $^{1}$ & $\begin{array}{c}25(\mathrm{OH}) \text {-Ergocalciferol } \\
(\mathrm{ng} / \mathrm{mL})\end{array}$ & $\begin{array}{l}25(\mathrm{OH})- \\
\text { Cholecalciferol } \\
\quad(\mathrm{ng} / \mathrm{mL})\end{array}$ & $\begin{array}{l}\text { Ergocalciferol } \\
\quad(\mathrm{ng} / \mathrm{mL})\end{array}$ & $\begin{array}{l}\text { Cholecalciferol } \\
\quad(\mathrm{ng} / \mathrm{mL})\end{array}$ & $\begin{array}{l}\alpha \text {-Tocopherol } \\
(\mu \mathrm{g} / \mathrm{mL})\end{array}$ & $\begin{array}{c}\beta \text {-Carotene } \\
(\mu \mathrm{g} / \mathrm{mL})\end{array}$ \\
\hline $0 \mathrm{~h}$ & $7 \pm 2^{\mathrm{a}}$ & $52 \pm 9^{\mathrm{a}}$ & $0 \pm 0^{\mathrm{a}}$ & $0 \pm 0^{\mathrm{a}}$ & $5.21 \pm 1.2^{\mathrm{a}}$ & $4.0 \pm 1.2$ \\
\hline $24 \mathrm{~h}$ & $34 \pm 7^{\mathrm{c}}$ & $96 \pm 16^{\mathrm{c}}$ & $99 \pm 15^{\mathrm{c}}$ & $163 \pm 16^{\mathrm{c}}$ & $6.55 \pm 1.7^{\mathrm{a}}$ & $4.4 \pm 1.6$ \\
\hline $30 \mathrm{~h}$ & $36 \pm 5^{\mathrm{d}}$ & $106 \pm 21^{\mathrm{d}}$ & $90 \pm 16^{\mathrm{d}}$ & $158 \pm 17^{\mathrm{c}}$ & $6.36 \pm 1.7^{\mathrm{a}}$ & $4.4 \pm 1.4$ \\
\hline Slaughter $(72-120 \mathrm{~h})$ & $39 \pm 13^{\mathrm{cd}}$ & $105 \pm 25^{\mathrm{cd}}$ & $36 \pm 17^{\mathrm{b}}$ & $75 \pm 29^{\mathrm{b}}$ & $5.36 \pm 1.1^{\mathrm{ab}}$ & $4.3 \pm 1.2$ \\
\hline
\end{tabular}

${ }^{\mathrm{a}-\mathrm{d}}$ Different superscripts indicate statistical differences within columns $(P \leq 0.05)$.

${ }^{1}$ Time after $250 \mathrm{mg}$ of ergocalciferol, $250 \mathrm{mg}$ of cholecalciferol, and 4,360 $\mathrm{mg}$ of all-rac- $\alpha$-tocopheryl acetate were placed in the rumen.

Initial plasma concentrations of $25(\mathrm{OH})$-ergocalciferol and $25(\mathrm{OH})$-cholecalciferol were $7 \pm 2$ and $52 \pm 9 \mathrm{ng} /$ $\mathrm{mL}$, respectively, and they increased to a plateau of $36 \pm 5$ and $106 \pm 21 \mathrm{ng} / \mathrm{mL}$ within the $30 \mathrm{~h}$ of sampling. Concentrations of 25(OH)-cholecalciferol were higher at all sampling times than the concentrations of $25(\mathrm{OH})$-ergocalciferol $(P \leq 0.001)$. No significant amounts of vitamin D metabolites other than $25(\mathrm{OH})$ ergocalciferol and 25(OH)-cholecalciferol were detected in the chromatograms. At slaughter between 72 or 120 $\mathrm{h}$ after placing the vitamins in the rumen, the concentrations of 25-hydroxy metabolites of ergocalciferol and cholecalciferol remained at the plateau level, indicating that the enzyme system in the liver was saturated. In contrast, the plasma concentrations of ergocalciferol and cholecalciferol had declined $(P \leq 0.05$; Table 1$)$ due to utilization for production of 25-hydroxy me- tabolites or through inactivation and degradation pathways eliminating ergocalciferol and cholecalciferol from plasma when circulating at pharmacological levels (Sommerfeldt et al., 1983).

The $\beta$-carotene concentration in plasma was constant at approximately $2 \mu \mathrm{g} / \mathrm{mL}$ in study 1 (Table 2) and approximately $4 \mu \mathrm{g} / \mathrm{mL}$ in study 2 (Table 1 ) at all sampling times.

In contrast to ergocalciferol and cholecalciferol, the plasma concentration of total $\alpha$-tocopherol showed no increase during the sample period (Table 2). However, the concentration of each of the 7 synthetic stereoisomers did increase during the first 24 to $30 \mathrm{~h}$ after ingestion of all-rac- $\alpha$-tocopheryl acetate $(P \leq 0.05)$, but the actual increase was very small and account for only 14 to $19 \%$ of the total $\alpha$-tocopherol in plasma (Table 2).



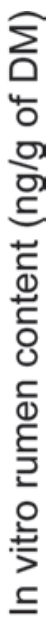

Time (h)

Figure 4. Ergocalciferol, cholecalciferol, $\alpha$-tocopherol, $\beta$-carotene, and lutein in ruminal content during a 30-h in vitro study. Slopes are not significantly different from zero in linear fits $(P>0.2)$. 
Table 2. Plasma concentrations (mean $\pm \mathrm{SD}$ ) of total $\alpha$-tocopherol, the 8 sterioisomers of $\alpha$-tocopherol, and $\beta$-carotene depending on the feed starch source

\begin{tabular}{|c|c|c|c|c|c|c|c|}
\hline Item $^{1}$ & $\begin{array}{c}\alpha \text {-Tocopherol } \\
(\mu \mathrm{g} / \mathrm{mL})\end{array}$ & $\begin{array}{c}2 \mathrm{~S}^{2} \\
(\mu \mathrm{g} / \mathrm{mL})\end{array}$ & $\begin{array}{c}\mathrm{RSS}^{3} \\
(\mu \mathrm{g} / \mathrm{mL})\end{array}$ & $\begin{array}{c}\mathrm{RRS}^{3} \\
(\mu \mathrm{g} / \mathrm{mL})\end{array}$ & $\begin{array}{c}\mathrm{RRR}^{4} \\
(\mu \mathrm{g} / \mathrm{mL})\end{array}$ & $\begin{array}{c}\mathrm{RSR}^{3} \\
(\mu \mathrm{g} / \mathrm{mL})\end{array}$ & $\begin{array}{c}\beta \text {-Carotene } \\
(\mu \mathrm{g} / \mathrm{mL})\end{array}$ \\
\hline \multicolumn{8}{|l|}{$\mathrm{NaOH}$} \\
\hline $0 \mathrm{~h}$ & $5.33 \pm 1.36$ & $0.07 \pm 0.01^{\mathrm{a}}$ & $0.25 \pm 0.08^{\mathrm{a}}$ & $0.22 \pm 0.06^{\mathrm{a}}$ & $4.62 \pm 1.19$ & $0.18 \pm 0.03^{\mathrm{ac}}$ & $2.4 \pm 1.1$ \\
\hline $24 \mathrm{~h}$ & $6.18 \pm 1.11$ & $0.12 \pm 0.01^{\mathrm{bc}}$ & $0.37 \pm 0.10^{\mathrm{bc}}$ & $0.34 \pm 0.07^{\mathrm{bc}}$ & $5.03 \pm 0.89$ & $0.31 \pm 0.07^{\mathrm{b}}$ & $2.5 \pm 0.9$ \\
\hline $30 \mathrm{~h}$ & $6.17 \pm 2.10$ & $0.11 \pm 0.02^{\mathrm{ac}}$ & $0.35 \pm 0.15^{\mathrm{ac}}$ & $0.35 \pm 0.14^{\mathrm{ac}}$ & $5.07 \pm 1.75$ & $0.28 \pm 0.08^{\mathrm{bc}}$ & $2.2 \pm 1.2$ \\
\hline \multicolumn{8}{|l|}{ Roll } \\
\hline $24 \mathrm{~h}$ & $5.93 \pm 2.92$ & $0.11 \pm 0.04^{\mathrm{b}}$ & $0.32 \pm 0.15^{\mathrm{ac}}$ & $0.29 \pm 0.17^{\mathrm{ac}}$ & $4.95 \pm 2.45$ & $0.26 \pm 0.11^{\mathrm{bc}}$ & $2.2 \pm 1.1$ \\
\hline $30 \mathrm{~h}$ & $6.43 \pm 2.86$ & $0.10 \pm 0.03^{\mathrm{b}}$ & $0.37 \pm 0.19^{\mathrm{bc}}$ & $0.35 \pm 0.16^{\mathrm{bc}}$ & $5.30 \pm 2.35$ & $0.30 \pm 0.13^{\mathrm{ac}}$ & $2.4 \pm 0.8$ \\
\hline
\end{tabular}

${ }^{\mathrm{a}-\mathrm{c}}$ Different superscripts indicate statistical differences within columns $(P \leq 0.05)$.

${ }^{1}$ Time after 4,360 mg of all-rac- $\alpha$-tocopheryl acetate was placed in the rumen. No difference between the sodium hydroxide (NaOH) and the rolled wheat (Roll) treatments was observed at any given time $(P>0.5)$.

${ }^{2}$ The sum of the $42 \mathrm{~S}$ stereoisomers of $\alpha$-tocopherol.

${ }^{3}$ Synthetic $2 \mathrm{R}$ sterioisomer of $\alpha$-tocopherol.

${ }^{4}$ The natural RRR stereoisomer of $\alpha$-tocopherol.

Numerically, RRR- $\alpha$-tocopherol increased by $0.5 \mu \mathrm{g} /$ $\mathrm{mL}$, and total $\alpha$-tocopherol increased by $0.8 \mu \mathrm{g} / \mathrm{mL}$ plasma. Thus, the increase in rate per milligram of ruminally introduced $\alpha$-tocopherol was 2.7 times below the rate of the increase in the plasma concentration of the sum of cholecalciferol and $25(\mathrm{OH})$-cholecalciferol per milligram of introduced cholecalciferol $(P \leq 0.05)$, and 1.6 times below the rate of the sum of ergocalciferol and 25(OH)-ergocalciferol per milligram of introduced ergocalciferol during the first $24 \mathrm{~h}$ after introducing the vitamins into the rumen. Plasma cholecalciferol and 25(OH)-cholecalciferol increased 1.7 times more per milligram of cholecalciferol introduced into the rumen than plasma ergocalciferol and 25(OH)-ergocalciferol per milligram of ergocalciferol introduced into the rumen $(P \leq 0.05)$ (Table 3).

\section{DISCUSSION}

In the present study, no indications of any degradation of ergocalciferol and cholecalciferol in the rumen were observed, either in vivo or during in vitro incubation in intact ruminal contents at $37^{\circ} \mathrm{C}$. An extremely limited amount of research has been carried out to study the fate of ergocalciferol and cholecalciferol in the rumen. Sommerfeldt et al. $(1979,1980)$ carried out in vitro experiments, where ${ }^{3} \mathrm{H}$-labeled ergocalciferol or cholecalciferol was incubated at $37^{\circ} \mathrm{C}$ under anaerobic conditions secured in a $\mathrm{CO}_{2}$ atmosphere with either intact or autoclaved ruminal fluid from cattle fed highroughage diets. Results showed that as little as 10 to $25 \%$ of the added radioactive label was present in ergocalciferol or cholecalciferol metabolites after $24 \mathrm{~h}$ of incubation in intact ruminal fluid, whereas no changes were found in autoclaved ruminal fluid, indicating that ruminal bacteria were responsible for the degradation of ergocalciferol and cholecalciferol metabolites (Sommerfeldt et al., 1979, 1980).

Earlier results regarding the ruminal fate of $\alpha$-tocopherol showed substantial degradation of the vitamin. Alderson et al. (1971) administered 20,000 IU of $\alpha$-tocopherol, chromium oxide, and polyethylene glycol to steers fed diets containing 20 to $80 \%$ corn and estimated the $\alpha$-tocopherol disappearance by calculating weighed averages of the ratios of $\alpha$-tocopherol to chromium oxide and polyethylene glycol in collected abomasal contents. They found that up to $45 \%$ of the administered $\alpha$-tocopherol, given in a single-dose gela-

Table 3. Relative increase in plasma concentration of major ergocalciferol and cholecalciferol metabolites and $\alpha$-tocopherol expressed as $\Delta(24,30)-0$ h plasma concentration $(\mathrm{ng})$ divided by the amount of vitamin placed in the rumen $(\mathrm{mg})$

\begin{tabular}{lccc}
\hline Item & $\begin{array}{c}\text { Ergocalciferol }+ \\
25(\mathrm{OH}) \text {-ergocalciferol }\end{array}$ & $\begin{array}{c}\text { Cholecalciferol }+ \\
25(\mathrm{OH}) \text {-cholecalciferol }\end{array}$ & $\alpha$-Tocopherol \\
\hline Plasma concentration $[\Delta(24,30)-0 \mathrm{~h}]^{1}$ & $0.49 \pm 0.07^{\mathrm{a}}$ & $0.84 \pm 0.10^{\mathrm{b}}$ & $0.31 \pm 0.35^{\mathrm{a}}$ \\
\hline${ }^{\mathrm{a}, \mathrm{b}}$ Different superscripts indicate statistical difference $(P \leq 0.05)$. & \\
${ }^{1}[\Delta(24,30)-0 \mathrm{~h}]=$ average of the plasma concentrations at 24 and $30 \mathrm{~h}$ minus the plasma concentration at \\
$0 \mathrm{~h}$.
\end{tabular}


tin capsule $24 \mathrm{~h}$ earlier, was missing from the abomasal contents. A significant effect of starch level in the feed ration was found, as the amount of lost $\alpha$-tocopherol increased with increasing starch levels in the feed. To account for $\alpha$-tocopherol taken up from the rumen, Alderson et al. (1971) sampled blood through a 24-h trial from both control sheep and sheep with a ligated pylorus that received 5,000 IU of $\alpha$-tocopherol. The conclusion was that no significant amount of $\alpha$-tocopherol was taken up from the rumen to the blood stream. These findings was indirectly supported by Hidiroglou and Jenkins (1974), who showed that plasma and tissue levels of radioactivity was higher when radioactively labeled 5-methyl-T- $\alpha$-tocopherol was administered directly into the duodenum than when it was administered into the rumen or abomasum of sheep.

In the present research, $\alpha$-tocopherol from all-rac$\alpha$-tocopheryl acetate was stable in the in vivo rumen study and in the in vitro incubation with ruminal contents of high-yielding dairy cows, regardless of starch type or level in the ration. Consistent with the present results, other research on the stability of $\alpha$-tocopherol, given as all-rac- $\alpha$-tocopheryl acetate, in the rumen has shown no degradation of $\alpha$-tocopherol in the rumen as measured in duodenal contents of sheep (Chikunya et al., 2004) or during in vitro incubation of $\alpha$-tocopherol in ruminal fluid from fasted sheep (Astrup et al., 1974), steers (McDiarmid et al., 1994), or cows (Weiss et al., 1995), or in intact ruminal contents from steers (Leedle et al., 1993). The findings of Alderson et al. (1971) might have been a result of incomplete extraction of $\alpha$-tocopherol from the duodenal contents analyzed in their experiments or implications to the chromium marker method used for estimating $\alpha$-tocopherol contents in the duodenal contents (Leedle et al., 1993).

$\beta$-Carotene and lutein, naturally occurring in feed, have been shown to be stable in incubation studies with both ruminal fluid from steers (Keating et al., 1964), which is in agreement with the present in vitro results and ruminal contents from sheep (Mora et al., 1999; Shorland et al., 1957). In the present study, in vivo results regarding $\beta$-carotene and lutein showed a constant level of the 2 carotenoids, which further emphasizes the fact that they are naturally present in the feed and follow the feed fraction in and out of the rumen. Because the free-alcohol form of $\alpha$-tocopherol followed the same pattern in vivo, it can be concluded that $\alpha$-tocopheryl acetate was not hydrolyzed into the alcohol form in the rumen.

The present research regarding uptake of ergocalciferol and cholecalciferol to the bloodstream, could indicate a different uptake of these vitamin D forms in the intestines of dairy cows (Hymøller et al., 2008). However, cholecalciferol has, in in vivo studies on rats, been reported to be taken up to the bloodstream by passive diffusion in the small intestine (Hollander et al., 1978), but whether ergocalciferol follows the same path, or even a similar path, has not been proven. The exact biochemical and physiological nature of the discrimination between ergocalciferol and cholecalciferol is yet to be determined. Different scenarios have been suggested in a variety of species, like a more rapid metabolism and clearance from plasma of ergocalciferol than cholecalciferol due to lower affinity of the plasmabased vitamin D-binding protein for ergocalciferol than for cholecalciferol, or a higher affinity of the liver-based vitamin D-25-hydroxylase enzyme for cholecalciferol than ergocalciferol, or maybe a combination of both (Nilsson et al., 1972; DeLuca et al., 1988; Armas et al., 2004). The latter is to some extend indirectly supported by the present results, because the relation between $25(\mathrm{OH})$-ergocalciferol and ergocalciferol was half of the relation between $25(\mathrm{OH})$-cholecalciferol and cholecalciferol after $24 \mathrm{~h}$, indicating that ergocalciferol is hydroxylated less frequently than cholecalciferol by the liver enzymes. Sommerfeldt et al. (1983) studied the uptake of ergocalciferol and cholecalciferol from the gastrointestinal tract of bull calves after feeding a single oral dose of $365 \mu \mathrm{Ci}$ either of $\left[{ }^{3} \mathrm{H}\right]$ ergocalciferol or $\left[{ }^{3} \mathrm{H}\right]$ cholecalciferol $(1.2 \mathrm{Ci} / \mathrm{mmol})$. Blood samples from the calves showed that ergocalciferol and cholecalciferol were the predominant forms circulating in plasma 10 to $15 \mathrm{~h}$ after the oral dose was given and that plasma concentrations peaked in 24 to $48 \mathrm{~h}$. The plasma concentrations of cholecalciferol and its metabolites in calves fed labeled cholecalciferol were at least twice as high as the concentrations of ergocalciferol and its metabolites in calves fed labeled ergocalciferol. Furthermore, the plasma concentrations of metabolites of ergocalciferol or cholecalciferol related to the inactivation and degradation of the vitamins in ergocalciferoltreated calves were found to be between 25 and $50 \%$ of the concentration of the respective metabolites in cholecalciferol-treated calves, indicating that there was no surplus vitamin to clear from the body in calves fed ergocalciferol. This lack of degradation products in plasma when ergocalciferol was fed does indicate that ergocalciferol might not enter the bloodstream to the same extent as cholecalciferol, attributing some of the discrimination between them to the intestines.

Plasma concentrations of the respective vitamins and derived metabolites responded very differently to a single dose supplementation of the 2 forms of vitamin D and all-rac- $\alpha$-tocopheryl acetate. Supplementation with ergocalciferol and cholecalciferol resulted in a substantial increase in plasma concentration of these vitamins, whereas supplementation with all-rac- $\alpha$-tocopheryl acetate did not result in any increase in the plasma 
concentration of $\alpha$-tocopherol of biological significance. The significant increase in the concentration of the 7 synthetic stereoisomers was numerically very small. This modest contribution and increase in the synthetic stereoisomers of $\alpha$-tocopherol in cows has previously been described (Meglia et al., 2006). Currently, it is not known whether this is caused by limited absorption or very specific biological discrimination toward the natural RRR stereoisomer (Jensen and Lauridsen, 2007), but the lack of increase in plasma concentration of $\alpha$-tocopherol following ruminal ingestion of $4,360 \mathrm{mg}$ of all-rac- $\alpha$-tocopheryl acetate indicates that the absorption of $\alpha$-tocopherol is the limiting step. In contrast to the vitamin $\mathrm{D}$ forms, all-rac- $\alpha$-tocopheryl acetate needs hydrolysis of its acetate ester before absorption, and in broilers, this step has been shown to be the ratelimiting step in the absorption of all-rac- $\alpha$-tocopheryl succinate (Jensen et al., 1999). It appears that singledose therapy is not an efficient way of boosting the plasma status of $\alpha$-tocopherol in cattle in contrast to boosting the plasma status of vitamin D through singledose therapy with cholecalciferol and, to some extent, ergocalciferol.

\section{CONCLUSIONS}

In the present study, no indications of any degradation of ergocalciferol and cholecalciferol were found in intact ruminal contents, either in vivo or during in vitro incubation. Also, all-rac- $\alpha$-tocopheryl acetate was stable in intact ruminal contents regardless of starch type or level in the ration fed to the cows. In plasma, cholecalciferol was found at significantly higher levels than ergocalciferol after ingestion of equal amounts of the 2 vitamin $\mathrm{D}$ forms, but the concentration of both forms increased significantly during the first few hours of sampling. The same difference was found in the 25-hydroxylated metabolites of the respective vitamin $\mathrm{D}$ forms. In contrast to that of ergocalciferol and cholecalciferol, the plasma concentration of $\alpha$-tocopherol showed no significant increase after ingestion of all-rac- $\alpha$-tocopheryl acetate and a very low ratio between $\alpha$-tocopherol ingested and $\alpha$-tocopherol in plasma, which indicates that absence of ruminal hydrolyzation enabling intestinal absorption of $\alpha$-tocopherol is the limiting step when explaining the low degrees of utilization of all-rac- $\alpha$-tocopheryl acetate encountered in dairy cattle and other ruminants.

\section{ACKNOWLEDGMENTS}

The authors thank N. B. Kristensen (Aarhus University, Faculty of Agricultural Sciences, Tjele, Denmark) for generously providing the cows used in this experiment and B. M. L. Raun (Aarhus University, Faculty of Agricultural Sciences, Tjele, Denmark) for assistance with the sampling. Landbrugets Hudefond, under the Danish Livestock and Meat Board (Copenhagen, Denmark), a Danish foundation with the aim of supporting agricultural activities financially, particularly within the cattle and beef sector, financed the study. Laboratory technical staff E. Lyng and M. Würtz (both from Aarhus University, Faculty of Agricultural Sciences, Tjele, Denmark) are acknowledged for their assistance with the laboratory analyses.

\section{REFERENCES}

Alderson, N. E., G. E. Mitchell, C. O. Little, R. E. Warner, and R. E. Tucker. 1971. Preintestinal disappearance of vitamin E in ruminants. J. Nutr. 101:655-659.

Armas, L. A. G., B. W. Hollis, and R. Heaney. 2004. Vitamin $D_{2}$ is much less effective than vitamin $\mathrm{D}_{3}$ in humans. J. Clin. Endocrinol. Metab. 89:5387-5391.

Astrup, H. N., S. C. Mills, L. J. Cook, and T. W. Scott. 1974. Stability of $\alpha$-tocopherol in rumen liquor of the sheep. Acta Vet. Scand. $15: 451-453$.

Bourne, N., D. C. Wathes, M. McGowan, and R. Laven. 2007. A comparison of the effects of parenteral and oral administration of supplementary vitamin $\mathrm{E}$ on plasma vitamin $\mathrm{E}$ concentrations in dairy cows at different stages of lactation. Livest. Sci. 106:57-64.

Chikunya, S., G. Demirel, M. Enser, J. D. Wood, R. G. Wilkinson, and L. A. Sinclair. 2004. Biohydrogenation of dietary n-3 PUFA and stability of ingested vitamin $\mathrm{E}$ in the rumen, and their effects on microbial activity in sheep. Br. J. Nutr. 91:539-550.

DeLuca, H. F., M. Nakada, Y. Tanaka, R. Sicinaki, and M. Phelps. 1988. The plasma binding protein for vitamin D is a site of discrimination against vitamin $\mathrm{D}_{2}$ compounds by the chick. Biochim. Biophys. Acta 965:16-21.

Hidiroglou, M., and K. L. Jenkins. 1974. Fate of radiotocopherol administered into the gastric system of sheep. Ann. Biol. Anim. Biochim. Biophys. 14:667-677.

Hidiroglou, N., L. R. McDowell, A. M. Papas, M. Antapli, and N. S. Wilkinson. 1992. Bioavailability of vitamin E compounds in lambs. J. Anim. Sci. 70:2556-2561.

Hollander, D., K. S. Muralidhara, and A. Zimmerman. 1978. Vitamin $\mathrm{D}_{3}$ intestinal absorption in vivo: Influence of fatty acids, bile salts, and perfusate $\mathrm{pH}$ on absorption. Gut 19:267-272.

Hymøller, L., S. K. Jensen, H. Lindqvist, B. Johansson, M. O. Nielsen, and E. Nadeau. 2009. Supplementing dairy steers and organically managed dairy cows with synthetic vitamin $\mathrm{D}_{3}$ is unnecessary at pasture during exposure to summer sunlight. J. Dairy Res. 76:372-378

Hymøller, L., S. K. Jensen, and M. O. Nielsen. 2008. Dairy cows might discriminate between vitamin D2 and vitamin D3 in the gastrointestinal tract. J. Dairy Sci. 91(E-Suppl. 1):481-482. (Abstr.)

Jensen, S. K., R. M. Engberg, and M. S. Hedemann. 1999. All-rac$\alpha$-tocopherol acetate is a better vitamin E source than all- $r a c-\alpha-$ tocopherol succinate for broilers. J. Nutr. 129:1355-1360.

Jensen, S. K., C. Jensen, K. Jakobsen, R. M. Engberg, J. O. Andersen, C. Lauridsen, P. Sørensen, P. Henckel, L. H. Skibsted, and G. Bertelsen. 1998. Supplementation of broiler diets with retinol acetate, $\beta$-carotene or canthaxanthin: Effect on vitamin and oxidative status of broilers in vivo and meat stability. Acta Agric. Scand. Anim. Sci. 48:28-37.

Jensen, S. K., and C. Lauridsen. 2007. $\alpha$-Tocopherol stereoisomers. Vitam. Horm. 76:281-308.

Keating, E. K., W. H. Hale, and F. Hubbert. 1964. In vitro degradation of vitamin A and carotene by rumen liquor. J. Anim. Sci. 23:111-117.

Leedle, R. A., J. A. Leedle, and M. D. Butine. 1993. Vitamin E is not degraded by ruminal microorganisms: Assessment with ruminal 
contents from a bull steer fed a high-concentrate diet. J. Anim. Sci. 71:3442-3450.

McDiarmid, R. E., W. Majak, and K. J. Cheng. 1994. Procedure for analysis of $\alpha$-tocopherol acetate in bovine ruminal fluid. Can. J. Anim. Sci. 74:391-392

Meglia, G. E., S. K. Jensen, C. Lauridsen, and K. P. Waller. 2006. $\alpha$-Tocopherol concentration and stereoisomer composition in plasma and milk from dairy cows fed natural or synthetic vitamin E around calving. J. Dairy Res. 73:227-234.

Mora, O., J. L. Romano, E. González, F. J. Ruiz, and A. Shimada. 1999. In vitro and in situ disappearance of $\beta$-carotene and lutein from lucerne (Medicago sativa) hay in bovine and caprine ruminal fluids. J. Sci. Food Agric. 79:273-276.

Nilsson, S. F., L. Östberg, and P. A. Peterson. 1972. Binding of vitamin D to its human carrier plasma protein. Biochem. Biophys. Res. Commun. 46:1380-1387.

Richardson, M. D., and S. Logendra. 1997. Ergosterol as an indicator of endophyte biomass in grass seeds. J. Agric. Food Chem. 45:3903-3907.

Shin, I. S., and F. N. Owens. 1990. Ruminal and intestinal disappearance of several sources of vitamin E. J. Anim. Sci. 68(Suppl. 1):544. (Abstr.)
Shorland, F. B., R. O. Weenink, A. T. Johns, and I. R. C. McDonald. 1957. The effect of sheep-rumen contents on unsaturated fatty acids. Biochem. J. 67:328-333.

Sommerfeldt, J. L., R. L. Horst, E. T. Littledike, and D. C. Beitz. 1979. In vitro degradation of cholecalciferol in rumen fluid. J. Dairy Sci. 62(Suppl. 1):192-193. (Abstr.)

Sommerfeldt, J. L., R. L. Horst, J. L. Napoli, D. C. Beitz, and E. T. Littledike. 1980. Evidence for in vitro production of vitamin $\mathrm{D}_{2}$ and vitamin $\mathrm{D}_{3}$ metabolites by rumen microbes. J. Dairy Sci. 63(Suppl. 1):88-89. (Abstr.)

Sommerfeldt, J. L., J. L. Napoli, E. T. Littledike, D. C. Beitz, and R. L. Horst. 1983. Metabolism of orally administered $\left[{ }^{3} \mathrm{H}\right]$ ergocalciferol and $\left[{ }^{3} \mathrm{H}\right]$ cholecalciferol by dairy calves. J. Nutr. 113:2595-2600.

Weiss, W. P., K. L. Smith, J. S. Hogan, and T. E. Steiner. 1995. Effect of forage to concentrate ratio on disappearance of vitamin $\mathrm{A}$ and E during in vitro ruminal fermentation. J. Dairy Sci. 78:18371842 